\title{
Swimming 'upstream' to tackle the social determinants of health
}

Tara Kiran, ${ }^{1,2,3}$ Andrew D Pinto ${ }^{1,2,3,4}$

\begin{abstract}
${ }^{1}$ Department of Family and Community Medicine,

St. Michael's Hospital, Toronto, Ontario, Canada

${ }^{2}$ Department of Family and Community Medicine, Faculty of Medicine, University of Toronto, Toronto, Ontario, Canada ${ }^{3}$ Centre for Research on Inner City Health, Li Ka Shing Knowledge Institute,

St. Michael's Hospital, Toronto, Ontario, Canada

${ }^{4}$ Division of Clinical Public Health, Dalla Lana School of Public Health, University of Toronto, Toronto, Ontario, Canada
\end{abstract}

\section{Correspondence to}

Dr Tara Kiran, Department of Family and Community Medicine, St. Michael's Hospital, 30 Bond Street, Toronto, Ontario, Canada M5B 1W8; tara.kiran@utoronto.ca

Accepted 10 December 2015 Published Online First

7 January 2016

\section{SLinked}

http://dx.doi.org/10.1136/ bmjqs-2015-004283

- http://dx.doi.org/10.1136/ bmjqs-2015-004584 - http://dx.doi.org/10.1136/ bmjqs-2015-004521

\section{CrossMark}

To cite: Kiran T, Pinto AD. BMJ Qual Saf 2016;25:

138-140.
Quality improvement interventions typically focus on how to improve the care delivered within healthcare organisations or by health systems. Rarely do efforts venture beyond the walls of clinics and hospitals to target the social determinants of health. Berkowitz et $a l^{1}$ remind us that swimming 'upstream' is essential if we want to improve health outcomes for vulnerable or disadvantaged patients. The authors conducted a cross-sectional study of a Health Leads intervention in two urban adult primary care practices. Social needs were identified and then addressed by advocates based in the practices. They found that $15 \%$ of patients seen had an unmet resource need, most commonly food insecurity or a health resource need such as difficulty obtaining health insurance or affording medications. Patients with unmet resource needs were less healthy, had more 'no-show' appointments, more emergency department visits and were less likely to meet care targets.

The association between social factors and health outcomes is well documented. ${ }^{2}$ To take just one of the chronic conditions discussed by Berkowitz et al, having or developing diabetes is more common in patients living in low income neighbourhoods. ${ }^{3-5}$ Living with a low income is a key determinant of being food insecure, a factor independently related to diabetes prevalence. ${ }^{6}$ The physical environment where one lives is strongly determined by one's income and is also associated with the occurrence of diabetes, likely through access to active transportation and healthy food sources. ${ }^{7}$ Patients with a low income are less likely to meet targets for cholesterol, blood pressure and glycaemic control ${ }^{8}$ and are more likely to have diabetes complications, even in a setting with universal health insurance. ${ }^{9}$ Finally, low income and other measures of social disadvantage are associated with higher mortality among people with diabetes. ${ }^{10} 11$
Despite these associations, few interventions to improve diabetes care tackle upstream factors. A large, well-conducted systematic review assessing the effectiveness of quality improvement strategies on diabetes management included 120 randomised trials testing interventions ranging from case management to audit and feedback. ${ }^{12}$ But out of 120 trials, not one attempted to address unmet social needs, including financial or food insecurity-factors that Berkowitz et al confirmed were associated with poorer glycaemic control. It makes intuitive sense that a patient with food insecurity, who cannot access their medications, and who has a difficult time affording transportation to attend health visits, would have a hard time managing their diabetes. Yet, our quality improvement interventions often do not address these fundamental factors.

Efforts to reduce non-urgent emergency department use have likewise largely overlooked social factors. ${ }^{13-15}$ Berkowitz et al found that patients with unmet resource needs were more than twice as likely to use the emergency department repeatedly in a year. They were not able to identify which resource need contributed to high emergency department use, likely because of their relatively small sample. However, their findings are consistent with other studies that have associated high use of the healthcare system with low-income status. ${ }^{16} 17$

Berkowitz et al did not find an association between resource use and cancer screening and attributed this to their own multifaceted intervention. ${ }^{18}$ Their intervention included intensive patient outreach for patients at high risk of not following up with screening and included efforts to address unmet resource needs such as transportation barriers. This work demonstrates that quality improvement can include actions that take into account social determinants. Their success in 
reducing socioeconomic disparities in cancer screening, however, may be more difficult to reproduce for chronic diseases like diabetes that require regular clinical visits, long-term behaviour change and sustained self-management.

Addressing the social determinants of health is essential to advance health equity. The 2001 Institute of Medicine report, Crossing the Quality Chasm, included 'equitable' as one of its six core aims for health system improvement stating that care should not vary based on personal characteristics such as gender, ethnicity or socioeconomic status. ${ }^{19}$ But, health systems should ensure not just that access to healthcare is equal but that access is fair. ${ }^{20}$ Equality describes sameness or difference, but equity is the absence of socially unjust or unfair health disparities. ${ }^{21}$ A focus on equity would mean that care might vary based on patient characteristics if certain subgroups need more intensive service delivery to improve health outcomes, as is the case for socially disadvantaged patients with diabetes. ${ }^{22}$

To go further than equity in access and to begin to discuss equity in health outcomes may make some healthcare leaders uncomfortable; others may find the task daunting. It requires judgements about what differences in health outcomes are unfair or avoidable and which are not. The article by Berkowitz et al reminds us that addressing inequities is necessary to improve clinical quality, that improving equity invariably means tackling the social determinants of health and that healthcare organisations have the ability to affect the social determinants.

How can we begin to 'swim upstream' in quality improvement work? First, healthcare organisations should be deliberate in efforts to uncover social factors that influence health, even when engaging in clinical microsystem improvement. Current quality improvement tools can inadvertently narrow our focus to the healthcare setting. Lean methodologies adapted from other industries can successfully improve efficiencies within a clinical setting but are not designed to help teams understand and influence the social factors influencing health. Process maps, cause and effect diagrams and Pareto charts can all similarly be focused only on the healthcare setting. We need to be intentional about having quality improvement tools include social causes, for example, including 'social determinants' as a category of causes in a cause and effect diagram.

Second, we should listen carefully to patients' experiences of self-care as these experiences may provide the most natural opportunity to identify social issues that are at the root of ill health and suboptimal disease management. We can use principles of Experience-Based Design ${ }^{23}$ to involve patients in co-designing services that meet not just their health needs but their social needs as well. We can go one step further and engage and listen to communities at risk to understand their needs and priorities. $^{24}$ Healthcare organisations can develop mutually beneficial partnerships with community agencies to address identified needs, engaging patients directly in their health where they live and work.

Third, we can identify and address unmet resource needs within the clinical setting. Screening tools like those used by Berkowitz et al offer a structured approach to detecting resource needs. Alternatively, clinicians can be coached to probe patients for contextual factors that may influence care. ${ }^{25} 26$ Electronic medical records can be a valuable medium for storing information on social factors, flagging actionable items and triggering automated or clinician-directed referrals. ${ }^{27}$ Referrals can connect patients to social workers, community workers, lawyers or others who can connect patients to appropriate resources or advocate on their behalf. ${ }^{28} 29$ These efforts should be rigorously studied to understand their impact on health and social factors as there is little research in this area to date. ${ }^{30}$

Berkowitz et al described a model where clinicians address the social determinants of health for individual patients encountered in their clinic. But to truly improve health equity, we need to swim even further upstream and engage in advocacy for an entire population. The WHO Commission on the Social Determinants of Health was explicit that to achieve health equity, we need to tackle the inequitable distribution of power, money and resources. ${ }^{20}$ Clinicians may feel uncomfortable with this calling but some would argue that advocacy is a logical extension of a healing, compassionate profession. In his moving address to Harvard Medical School graduates, Don Berwick urges graduating doctors not just to cure the disease, but to 'cure the killer injustice'.

Twitter Follow Tara Kiran at @ tara_kiran and Andrew Pinto at @AndrewDPinto

Competing interests None declared.

Provenance and peer review Commissioned; internally peer reviewed.

\section{REFERENCES}

1 Berkowitz SA, Hulberg AC, Hong C, et al. Addressing basic resource needs to improve primary care quality: a community collaboration programme. BMJ Qual Saf 2016;25:

164-72.

2 Commission on the Social Determinants of Health. Closing the gap in a generation: Health equity through action on the social determinants of health. final report of the commission on social determinants of health. Geneva, Switzerland: World Health Organization, 2008.

3 Beckles GL, Chou CF, Centers for Disease Control and Prevention (CDC). Diabetes-United States, 2006 and 2010. MMWR Surveill Summ 2013;62(Suppl 3):99-104.

4 Gatineau M, Hancock C, Holman N, et al. Adult obesity and type 2 diabetes. London, UK: Public Health England, 2014.

5 Ross NA, Gilmour HL, Dasgupta K. 14-year diabetes incidence: the role of socio-economic status: Statistics Canada, 2010. 
6 Seligman HK, Bindman AB, Vittinghoff E, et al. Food insecurity is associated with diabetes mellitus: results from the National Health Examination and Nutrition Examination Survey (NHANES) 1999-2002. J Gen Intern Med 2007;22:1018-23.

7 Glazier RH, Creatore MI, Weyman JT, et al. Density, destinations or both? a comparison of measures of walkability in relation to transportation behaviors, obesity and diabetes in Toronto, Canada. PLOS ONE 2014;9; 85295.

8 Walker RJ, Smalls BL, Campbell JA, et al. Impact of social determinants of health on outcomes for type 2 diabetes: a systematic review. Endocrine 2014;47:29-48.

9 Booth GL, Lipscombe LL, Bhattacharyya O, et al. Diabetes. In: Bierman A, eds. Project for an Ontario Women's Health Evidence-Based Report. Toronto, 2010.

10 Lipscombe LL, Austin PC, Manuel DG, et al. Income-related differences in mortality among people with diabetes mellitus. CMAJ 2010;182:E1-17.

11 Saydah S, Lochner K. Socioeconomic status and risk of diabetes-related mortality in the US. Public Health Rep 2010;125:377.

12 Tricco AC, Ivers NM, Grimshaw JM, et al. Effectiveness of quality improvement strategies on the management of diabetes: a systematic review and meta-analysis. Lancet 2012;379:2252-61.

13 Althaus F, Paroz S, Hugli O, et al. Effectiveness of interventions targeting frequent users of emergency departments: a systematic review. Ann Emerg Med 2011;58:41-52. e42.

14 Flores-Mateo G, Violan-Fors C, Carrillo-Santisteve P, et al. Effectiveness of organizational interventions to reduce emergency department utilization: a systematic review. PLoS ONE 2012;7:e35903.

15 Uscher-Pines L, Pines J, Kellermann A, et al. Emergency department visits for nonurgent conditions: systematic literature review. Am J Manag Care 2013;19:47-59.

16 Roos N, Burchill C, Carriere K. Who are the high hospital users? a Canadian case study. J Health Serv Res Policy 2003;8:5-10.

17 Rosella LC, Fitzpatrick T, Wodchis WP, et al. High-cost health care users in Ontario, Canada: demographic, socio-economic, and health status characteristics. BMC Health Serv Res 2014;14:532.
18 Berkowitz SA, Percac-Lima S, Ashburner JM, et al. Building equity improvement into quality improvement: reducing socioeconomic disparities in colorectal cancer screening as part of population health management. J Gen Intern Med 2015;30:942-9.

19 Committee on Quality Health Care in America. Crossing the quality chasm: a new health system for the 21st century. Washington DC: Institute of Medicine, 2001.

20 Marmot M, Friel S, Bell R, et al. Health CoSDo. Closing the gap in a generation: health equity through action on the social determinants of health. Lancet 2008;372:1661-9.

21 Kawachi I, Subramanian S, Almeida-Filho N. A glossary for health inequalities. J Epidemiol Community Health 2002;56: 647-52.

22 Glazier RH, Bajcar J, Kennie NR, et al. A systematic review of interventions to improve diabetes care in socially disadvantaged populations. Diabetes Care 2006;29:1675-88.

23 Bate P, Robert G. Experience-based design: from redesigning the system around the patient to co-designing services with the patient. Qual Saf Health Care 2006;15:307-10.

24 Wong WF, LaVeist TA, Sharfstein JM. Achieving health equity by design. JAMA 2015;313:1417-18.

25 Raza D, Bloch G, Kulie S. Office interventions for poverty. Ontario Med Rev 2013:21-4. http://www.oma.org/Resources/ Documents/Oct13_OMR_Poverty_feature2.pdf

26 Schwartz A, Weiner SJ, Binns-Calvey A, et al. Providers contextualise care more often when they discover patient context by asking: meta-analysis of three primary data sets. BMJ Qual Saf 2016;25:159-63.

27 Gottlieb LM, Tirozzi KJ, Manchanda R, et al. Moving electronic medical records upstream: incorporating social determinants of health. Am J Prev Med 2015;48:215-18.

28 Beck AF, Henize AW, Kahn RS, et al. Forging a Pediatric Primary Care-Community Partnership to Support Food-Insecure Families. Pediatrics 2014;134:e564-71.

29 Cohen E, Fullerton DF, Retkin R, et al. Medical-legal partnership: collaborating with lawyers to identify and address health disparities. J Gen Intern Med 2010;25:136-9.

30 Adams J, White M, Moffatt S, et al. A systematic review of the health, social and financial impacts of welfare rights advice delivered in healthcare settings. BMC Public Health 2006;6:81.

31 Berwick DM. To isaiah. JAMA 2012;307:2597-9. 